\title{
All1025611?5
}

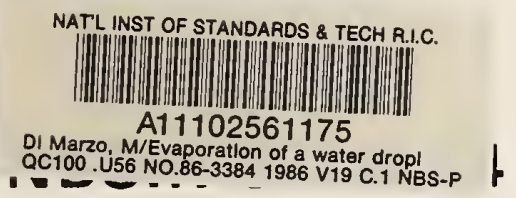

\section{Evaporation of A Water Droplet Deposited on A Hot High Thermal Conductivity Solid Surface}

Marino di Marzo

Mechanical Engineering Department

University of Maryland

College Park, MD 20742

David D. Evans

U.S. DEPARTMENT OF COMMERCE

National Bureau of Standards

National Engineering Laboratory

Center for Fire Research

Gaithersburg, MD 20899

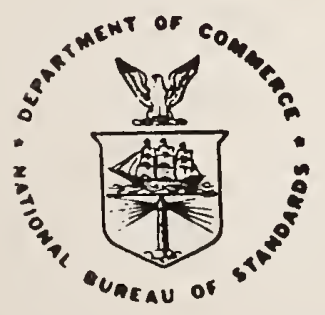

U.S. DEPARTMENT OF COMMERCE

NATIONAL BUREAU OF STANDARDS

$-O C$ 

ค.

\section{EVAPORATION OF A WATER DROPLET DEPOSITED ON A HOT HIGH THERMAL CONDUCTIVITY SOLID SURFACE}

Marino di Marzo

Mechanical Engineering Department University of Maryland

College Park, MD 20742

David D. Evans

U.S. DEPARTMENT OF COMMERCE National Bureau of Standards National Engineering Laboratory Center for Fire Research Gaithersburg, MD 20899

August 1986

U.S. DEPARTMENT OF COMMERCE, Malcolm Baldrige, Secretary NATIONAL BUREAU OF STANDARDS. Ernest Ambler, Director 
LIST OF FIGURES $\ldots \ldots \ldots \ldots \ldots \ldots \ldots \ldots \ldots \ldots \ldots \ldots \ldots \ldots \ldots \ldots \ldots \ldots \ldots \ldots \ldots \ldots$ iv

Abstract $\ldots \ldots \ldots \ldots \ldots \ldots \ldots \ldots \ldots \ldots \ldots \ldots \ldots \ldots \ldots \ldots \ldots \ldots \ldots \ldots \ldots \ldots \ldots \ldots \ldots \ldots \ldots \ldots \ldots \ldots$

1. INTRODUCTION $\ldots \ldots \ldots \ldots \ldots \ldots \ldots \ldots \ldots \ldots \ldots \ldots \ldots \ldots \ldots \ldots \ldots \ldots \ldots \ldots \ldots \ldots \ldots \ldots \ldots \ldots . . \ldots$

2. PHENOMENOLOGY ......................................... 3

2.1 Radius of the Wetted Region .......................... 4

2.2 Droplet Shape $\ldots \ldots \ldots \ldots \ldots \ldots \ldots \ldots \ldots \ldots \ldots \ldots \ldots \ldots \ldots \ldots \ldots \ldots \ldots \ldots \ldots . \ldots \ldots$

3. THEORETICAL EVAPORATION TIME $\ldots \ldots \ldots \ldots \ldots \ldots \ldots \ldots \ldots \ldots \ldots \ldots \ldots \ldots \ldots \ldots \ldots \ldots \ldots \ldots . . \ldots$

3.1 Solid Surface Temperature ............................. 9

3.2 Liquid-Vapor Interfacial Molar Fraction .................. 9

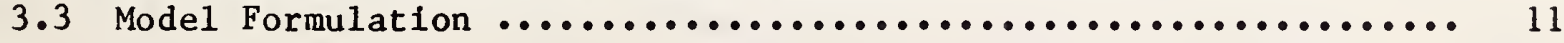

4. MODEL VALIDATION $\ldots \ldots \ldots \ldots \ldots \ldots \ldots \ldots \ldots \ldots \ldots \ldots \ldots \ldots \ldots \ldots \ldots \ldots \ldots \ldots \ldots \ldots \ldots \ldots \ldots \ldots \ldots$

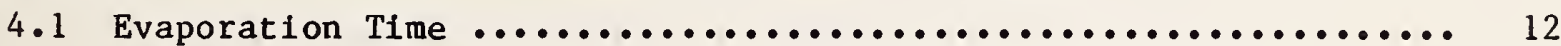

4.2 Detailed Features $\ldots \ldots \ldots \ldots \ldots \ldots \ldots \ldots \ldots \ldots \ldots \ldots \ldots \ldots \ldots \ldots \ldots \ldots \ldots \ldots \ldots \ldots$

5. CONCLUSIONS .......................................... 15

6. ACKNOWLEDGMENTS ....................................... 16

7. REFERENCES ........................................... 16

8. NOMENCLATURE $\ldots \ldots \ldots \ldots \ldots \ldots \ldots \ldots \ldots \ldots \ldots \ldots \ldots \ldots \ldots \ldots \ldots \ldots \ldots \ldots \ldots \ldots \ldots \ldots \ldots \ldots$ 


\section{LIST OF FIGURES}

Page

Figure 1. Typical droplet evaporation behavior

Figure 2. Characterization of the parameter $\beta_{0}$

Figure 3. Solid-liquid angle of contact versus the wetting parameter $\beta_{0}$

Figure 4. Characterization of the convective heat transfer

coefficient ....................................

Figure 5. Evaporation time as a function of the initial solid

surface temperature and droplet volume ................

Figure 6. Evaporation time: theory versus experiments ............ 24

Figure 7 . Evaporative heat flux comparison ................... 25

Figure 8 . Liquid water inventory versus time ................. 26

Figure 9. Temporal heat flux behavior $\ldots \ldots \ldots \ldots \ldots \ldots \ldots \ldots \ldots \ldots \ldots \ldots \ldots$

Figure 10. Spacial heat flux behavior $\ldots \ldots \ldots \ldots \ldots \ldots \ldots \ldots \ldots \ldots \ldots$ 


\section{EVAPORATION OF A WATER DROPLET DEPOSITED ON A HOT HIGH THERMAL CONDUCTIVITY SOLID SUREACE \\ David D. Evans and Marino di Marzo}

\section{Abstract}

A model is presented that predicts major features of the evaporation of water droplets deposited on a hot non-porous solid surface. In the temperature range of interest, nucleate boiling heat transfer is fully suppressed, hence the model is only concerned with the evaporative process. In the model, the solid material is assumed to have high thermal conductivity and diffusivity, so that the surface temperature under the water droplet can be considered uniform. The temperature of this portion of a larger solid surface covered by the liquid is calculated from the classic solution for contact temperature between two semi-infinite bodies. The liquid-vapor interfacial temperature and the water-vapor molar fraction in the air at the exposed surface of the water droplet are deduced from the coupled heat and mass transfer energy balance at the interface. Spatial and temporal integration of the overall droplet energy equation is used to predict the droplet evaporation time and the instantaneous evaporation rate. Model predictions for the total evaporation time and temporal variation of the droplet volume agree well with experiments performed using a heated aluminum block. The model is used to quantify spacial and temporal heat fluxes distribution at the exposed surface of the water droplet.

Key words: cooling, droplets, evaporation cooling, extinguishing, spray quenching, sprinkler system, water sprays. 


\section{INTRODUCTION}

Many studies have been performed to quantify the vaporization process for both single droplets and multiple droplet arrays impacting on hot surfaces. For the studies found in the published literature, the full span of the droplet vaporization processes including boiling phenomena are usually reported. These would include evaporation, nucleate boiling, film boiling, and Leidenfrost transition. This present investigation is more limited in the span of vaporization processes studied, being only concerned with the evaporation of a single droplet on a hot surface. The study does report very detailed results for spatial and temporal variation of the heat flux at the exposed surface of the droplet, and for temporal variation of the droplet volume. Exclusive study of the evaporative process implies that conditions are maintained under which nucleate boiling is fully suppressed.

This detailed study of water droplet evaporation is intended to form the basis for a simple thermal model of solid fuel fire extinguishment. Depending on the type of solid fuel that is burning, the surface may take many different configurations having greatly different responses to water droplets impact. Common natural solid fuels produce low thermal conductivity chars. Some manufactured materials such as thermoplastics may form a shallow liquid $\mathrm{f} 1 \mathrm{~lm}$ on the solid surface, others produce a non-porous surface. This work is a first phase of an extensive research program concerned with a series of conditions that must be evaluated in order to construct accurate droplet cooling models for the many different surfaces that may be generated by burning of solid fuels. 
The thermal conductivity/diffusivity of common solid fuels is very low compared to those of metals. This implies that the local cooling induced by the droplet evaporation is more severe. The heat fluxes from the solid under the droplet are not large enough to sustain nucleate boiling, hence evaporation is the mode of heat transfer to be considered. In this first investigation, aluminum was selected as the solid material for the purpose of comparing the experimental results with those of other investigators. At present, abundant information is avallable only for droplet deposited on metal bodies.

Results of several previous investigations of droplet evaporation have been drawn upon in the process of formulating analytical portions of the model for droplet evaporation presented in this study. Seki [1] has demonstrated good agreement between the theoretically based computations of the solidliquid contact temperature and experimental measurements. The works of Michiyoshi and Makino [2,3,4] establish the thermal behavior of the droplets during the evaporative process. Zhang [5] describes the droplet shape as spherical segments, which proved to be a rather accurate description for droplets observed in this study. The model for the droplet evaporative process presented in this paper represents improvements to the previous models formulated by Bonacina [6] and Rizza [7].

\section{PHENOMENOLOGY}

A spherical droplet upon lmpacting a solid surface spreads on it. The final configuration of the liquid varies a great deal and depends on a multitude of parameters. For the case of liquid water impinging a surface at near water saturation temperature, the shape can be regarded as a spherical segment 
[5]. Note that, in this study, the droplet is considered to be homogeneous in the liquid phase at all times, and evaporation at the liquid-vapor interface is the only means of generating the vapor phase. Experimentally, small stationary bubbles are observed at times on the solid surface under the droplet spherical segment [2]. However, these small bubbles are minimal. in volume and don't seem to affect the evaporation process significantly.

\subsection{Radius of the Wetted Region}

The radius of the wetted area is a very important parameter, as recognized by Bonicina [6] and other investigators. In the literature, the radius of the wetted area is non-dimensionalized with the radius of the equivalent initial liquid volume spherical shape forming the parameter $\beta_{0}$. For droplets "softly" deposited on the surface (droplet release from height less than 1 centimeter), a value of $\beta_{0}$ in the range 1.2 to 1.5 is observed. However, for sprayed water, several investigators have reported values of $B_{0}$ up to $4.5[6,7]$. In this study the interest is on "softly" deposited droplet. It is crucial to note that these values of $B_{0}$ are referred to the initial condition at deposition before evaporation begins $(t=0)$. Values for the more general parameter $B$ based on the liquid volume at any time during the evaporation process can be calculated at any stage of the evaporative process using as a reference the radius of the spherical droplet of equal volume. Figure 1 depicts the various phases of the evaporation of a "softly" deposited droplet. Note that the radius of the wetted area is constant throughout most (90 to 95 percent) of the evaporative process. 
The importance of the parameter $\beta$ is that it accounts for the effects of a number of variables that characterize the surface conditions (wettability, roughness, etc.), the fluid (surface tension, wetting ability, etc.) and the droplet deposition process. All the experimental data were obtained for pure, degassed and de-ionized water droplets deposited on an aluminum block with the exposed source coated with a very thin $(\simeq 0.06 \mu \mathrm{m})$ chromium layer. The chromium was vapor deposited on the aluminum to obtain a polished (roughness of $0.1-0.15 \mu \mathrm{m})$, scratch resistance surface. Prior to each droplet deposition the surface was cleaned with ethyl alcohol in order to remove particles and grease. In spite of this careful procedure some scatter in the experimental data was observed. This scatter is due mainly to the deposition technique, in which there was some uncertainty in positioning the hypodermic needle used to dispense the water above the surface. Due to the advancing/receding angles hysteresis, when the needle is retracted, in some occasions the angle of contact between the liquid and the solid was less than the advancing angle (e.g•, the largest angle possible). In order to obtain a meaningful information for the value of $\beta_{0}$, a large data base was compiled. For each temperature considered ( 7 values between 75 and $100^{\circ} \mathrm{C}$ ) and for each volume considered ( 5 between 10 and $50 \times 10^{-9} \mathrm{~m}^{3}$ ) ten values of $\beta_{0}$ were collected for a total of 350 data points. No systematic variation with volume was found because, in the limited range of droplet volume of interest, the values of $\beta_{0}$ obtained for the various volumes were not clearly distinguishable.

The temperature dependence of $\beta_{0}$ was more evident and, as illustrated in Fig. 2, the mean values and the standard deviation of the wetting parameter are plotted versus the initial solid surface temperature. Most of the data 
especially in the low temperature range lies in the five percent band about the linear regression of the average values which is given by

$$
\beta_{0}=0.009 \mathrm{~T}_{s_{0}}+0.6
$$

This analytical representation will be used in the following to provide values for the wetting parameter $\beta_{0}$. The range of droplet sizes of interest to this analysis is dictated by the actual size of the droplets delivered by the fire suppression equipment.

\subsection{Droplet Shape}

An analytical formulation defining the surface of a spherical segment in cylindrical coordinates is given by

$$
y=\left(B^{2}-r^{2}\right)^{1 / 2}-A
$$

where $A$ and $B$ are constants. By equating the volume of the droplet in spherical configuration to the volume of the droplet in spherical segment configuration (and by imposing that at the droplet outer edge 1ts thickness is zero), the thickness of the droplet at its apex, a, can be written as

$$
a=R\left[4 / \beta^{3}+\left(1+16 / \beta^{6}\right)^{1 / 2}\right]^{1 / 3}+\left[4 / \beta^{3}-\left(1+16 / \beta^{6}\right)^{1 / 2}\right]^{1 / 3}
$$

With these two conditions obtain

$$
A=\left(\frac{R}{2}\right)\left(\frac{1}{\gamma}-\gamma\right)
$$


and

$$
B=\left(\frac{R}{2}\right)\left(\frac{1}{\gamma}+\gamma\right)
$$

where $\gamma$ equals $a / R$. Therefore, by introducing non-dimensional coordinates, the equation for the droplet shape can be written as

$$
s=\left[\frac{(1 / \gamma+\gamma)^{2}}{4}-z^{2}\right]^{1 / 2}-\frac{(1 / \gamma-\gamma)}{2}
$$

where $s$ is $y / R$ and $z$ is $r / R$.

In order to evaluate how well the droplet shape agrees with the assumed spherical segment shape, the solid-liquid angle of contact $\alpha$ is calculated and compared with the measured values from photographs of water droplets "softly" deposited on a polished aluminum surface. By differentiating Eq. (6) with respect to $z$, at $z=1$, and substituting the value for $\gamma$ obtained from Eq. (3), the angle $\alpha$ is evaluated as

$$
\theta=\operatorname{arctg}\left[\frac{1}{\frac{(1 / \gamma+\gamma)^{2}}{4}-1}\right]^{1 / 2}
$$

Figure 3 shows that good agreement is found between measured and computed values for droplets just deposited on the surface and during the evaporation process. This occurrence was also reported by Zhang [5] in his optical investigation of the droplet behavior. 


\section{THEORETICAL EVAPORATION TIME}

The high thermal conductivity and diffusivity of the metal solid suggest that the temperature of the solid surface under the droplet can be assumed constant during the evaporative process. This assumption implicitly uncouples the solid substrate properties from the evaporation process. For the case of a low conductivity/diffusivity material it is anticipated that such uncoupling will not be possible.

The assumption that $\beta_{0}$ is a function of the temperature only is less justifiable, however, two points need to be mentioned in this respect:

(a) the measured dependence of $\beta_{0}$ on the volume is rather erratic. Variations are introduced by different local surface conditions, and by different droplet deposition procedures. In splte of numerous experiments, a clearly defined dependence of $\beta_{0}$ on any parameter but temperature.

(b) the evaporation time is not an extremely strong function of $B_{0}$. $A^{A}$ rationale for this can be explained by noting that, as the liquid evaporates, $\beta$ increases and its value quickly becomes independent of the initial conditions. The evaporation rate in the inftial portion of the process constitutes a minor contribution to the overall phenomenon (as will be shown); it will become clear that any inftial variations of the parameter $B$ are rapidly eliminated and do not influence the overall process significantly. 


\subsection{Solid Surface Temperature}

Seki [1] gives an interesting method to evaluate the solid surface temperature in the wetted region. By referring to the semi-infinite body solution for sudden surface temperature change, he evaluates the surface temperature as

$$
T_{s}=\frac{T_{s o} \sqrt{C_{s} \rho_{s} k_{s}}+T_{w o} \sqrt{C_{w} \rho_{w} k}}{\sqrt{C_{s} \rho_{s} k_{s}}+\sqrt{C_{w} \rho_{w} k_{w}}}
$$

The temperature for water near saturation (on metallic surfaces) behaves in very good agreement with this model as documented in Seki's work [1]. Note that Michiyoshi confirms that the liquid-solid interfacial temperature can be considered constant in the evaporation process $[2,4]$.

\subsection{Liquid-Vapor Interfacial Molar Fraction}

In order to evaluate the liquid-vapor interfacial molar fraction, mass transfer as well as heat transfer must be considered. The heat balance at the interface is

$$
q_{c}=W \Lambda M_{w}=h\left(T_{i}-T_{a}\right)
$$

where $W$ is the molar flux of the vapor at the water-air interface, the molar flux is due to the contribution of the diffusive and overall fluxes; that is

$$
W=h_{m}\left(\rho_{a} / M_{a}\right)\left(x_{i}-x_{a}\right)+x_{i} W
$$


By rearranging and by noting that the heat is transferred through the liquid only by conduction, one obtains

$$
\frac{k_{w}\left(T_{s}-T_{i}\right)}{R s}=\left[\frac{x_{i}-x_{a}}{1-x_{i}}\right] \rho_{a} h_{m} \Lambda\left[\frac{M_{W}}{M_{a}}\right]+h\left(T_{i}-T_{a}\right)
$$

The Chilton-Colburn analogy [8] relates the mass transfer coefficient $h_{m}$ to the convective heat transfer coefficient $h$ by the following expression

$$
\mathrm{h}_{\mathrm{m}}=\frac{\mathrm{h}}{\rho_{\mathrm{a}} \mathrm{c}_{\mathrm{a}}}\left[\frac{\mathrm{D}}{\alpha_{\mathrm{a}}}\right]^{2 / 3}
$$

By combining Eqs. (11) and (12) and noting that the water-air molecular weight ratio is 0.624 , yields

$$
\frac{k_{W}}{R h s}\left(T_{s}-T_{i}\right)=0.624\left[\frac{D}{\alpha_{a}}\right]^{2 / 3}\left[\frac{\Lambda}{c_{a}}\right]\left[\frac{x_{i}-x_{a}}{1-x_{i}}\right]+\left(T_{i}-T_{a}\right)
$$

Note that the only unknown is $x_{1}$, since the interfacial temperature $T_{1}$ is the saturation temperature of steam at the pressure corresponding to its molar fraction. For a given liquid layer thickness ( $\cdot s)$, the molar fraction can be determined via an iteration procedure. Furthermore, the left hand side of this equation is finite at $r=R$ if the temperature at the droplet exposed surface coincides with the solid surface temperature. This condition seems reasonable and it is used to determine the vapor molar fraction in the air at the outer edge of the droplet.

The convective term accounts for less than 2 percent of the evaporative heat transfer, therefore, it could be neglected; however, the convective heat transfer coefficient is paramount because it determines the mass transfer 
coefficient. The heat flux through the block is determined measuring the temperature gradient across a layer of glass of known thermal conductivity inserted under the aluminum block. The lateral surface of the glass layer and of the aluminum block are insulated to insure one dimensional heat flux in the vertical direction. A silicon heat sink compound paste is used to guarantee effective contact between the glass and the aluminum block. With this procedure the heat flux is measured within 5-6 percent accuracy. The block surface temperature and the ambient temperature are measured to determine the convective heat transfer coefficient once the heat flux is known. The experimental measurements for the convective heat transfer coefficient are illustrated in Fig. 4. The linear regression of these data is given by

$$
h=0.098 \mathrm{~T}_{\mathrm{s}_{0}}+2.8
$$

Note that this is the solid surface to air heat transfer coefficient and it is assumed that the droplet does not affect greatly the convection pattern associated with the much larger heated solid surface. The radiation contribution is in the order of 4 percent and it is accounted for in the experimental determination of $h$.

\subsection{Model Formulation}

An overall heat balance on the droplet can be written for the small time interval $\mathrm{dt}$ as

$$
\left\{2 \pi R^{2} \int_{0}^{1} q_{e} z d z\right\} d t=-\Lambda \rho_{w} d V
$$


where $q_{e}$ is the evaporative heat flux, that is

$$
\mathrm{q}_{\mathrm{e}}=0.624 \mathrm{~h}\left(\frac{\Lambda}{a_{a}}\right)\left(\frac{D}{c_{a}}\right)^{2 / 3}\left[\frac{x_{i}-x_{a}}{1-x_{i}}\right]
$$

The instantaneous rate of evaporation is then

$$
-\frac{d V}{d t}=\frac{2 \pi R^{2}(0.624) h}{\rho_{w} c_{a}}\left[\frac{D}{\alpha_{a}}\right]^{2 / 3} \int_{0}^{1}\left[\frac{x_{i}-x_{a}}{1-x_{i}}\right] z d z
$$

and $x_{i}$ is function both of $z$ and $t$.

The initial volume being known, a numerical technique allows one to determine the total evaporation time from Eq. (17). Note that at each time step the evaporative mass flux is obtained by computing the integral in the right hand side of the equation.

\section{MODEL VALIDATION}

The details of the experimental set up and of the data acquisition are described in detail in reference [9].

\subsection{Evaporation Time}

Figure 5 illustrates the comparison of results between the computations of the model developed in this study and experiments. Good agreement 18 observed. The discrepancies at the high temperatures and large droplets diameters are due to a number of factors. The influence of the droplet on the convective heat transfer coefficient and slight variation in the solld-liquld 
interfacial temperature coupled with uncertainties in the various experimental data acquisition are the most probable factors.

Figure 6 shows a comparison of the total evaporation time measured and calculated for a large number of experiments conducted in this study as well as in others. In all these experiments, the droplet volume range between 10 and $50 \times 10^{-9}$ cubic meters, and the initial surface temperature is in the range 75 to $100^{\circ} \mathrm{C}$.

In Fig. 7 experimental data by Michiyoshi and Makino [2,3] are compared with experimental data of Trehan [9] and with the theoretical computations. The data by Michiyoshi and Makino are for droplet volumes between $9 \times 10^{-9}$ and $19 \times 10^{9} \mathrm{~m}^{3}$, the other data are for droplets in the range $20 \times 10^{-9} \mathrm{~m}^{3}$ to $50 \times 10^{-9} \mathrm{~m}^{3}$ in volume. All this information is concerned with the average heat flux for various initial surface temperatures. The most important finding is that the solid material (e.g•, aluminum, copper, steel) do not have a strong influence on the phenomena. The theory provides an extremely good representation of the data by Michiyoshi and Makino. The exponential behavior of the heat flux (hence of the time) with respect to the initial surface temperature must be noted. The volume dependence is more complex but less strong •

\subsection{Detailed Features}

To further validate the model, the normalized liquid volume is plotted versus the time, non-dimensionalized with respect to the total evaporation time, in Fig. 8. Very good agreement is found for the data which were obtained from measurements of the photographic sequence shown in Fig. 1. 
It is interesting to deduce information concerning the temporal and spacial distribution of the heat flux on the droplet-to-air interface from the model calculations. Figure 9 shows model predictions of the heat flux variations during the evaporation process. The corresponding spatial heat flux distribution is presented in Fig. 10. The high heat flux at the droplet outer edge is evident. Note that for three quarters of the total evaporation time the central portion of the droplet liquid-vapor interface does not contribute much to the process; in the last quarter, the dramatic flux increase is produced by the contribution of most of the droplet surface because the reduced thickness of the droplet enhances the heat transfer by conduction in the liquid layer. The predominant contribution of the outer edge of the droplet to the evaporative process is well documented in the literature and it is often associated with the Maragoni effect [10].

Michiyoshi [4] observed that the temperatures at the solid surface and at a fixed point above it (in the liquid) are constant during the evaporation process. This face implies that the heat flux is also constant. The results just shown confirm that during most of the evaporation process, in the region close to the droplet symmetry axis, the heat flux does not vary significantly.

These results also show that the heat flux at the droplet edge can be as high as three times the spatial average heat flux at the beginning of the evaporative process. As the phenomenon progresses, the spatial average heat flux increases but the flux distribution in the radial direction becomes less important. Note that the droplet under consideration has a radius of about $3 \times 10^{-3} \mathrm{~m}$ and that a gradient of $1^{\circ} \mathrm{C}$ across that distance produces a heat flux of more than $40,000 \mathrm{~W} / \mathrm{m}^{-2}$ in aluminum. It follows that the hypothesis of 
uniform temperature distribution under the droplet seems reasonable since the temporal and spacial average heat flux for this case is of about $50,000 \mathrm{~W} / \mathrm{m}^{-2}$. The application of this simple boundary condition to the case of low thermal conductivity/diffusivity solid materials is not possible and a significant temperature distribution in the radial direction under the droplet is expected. To solve this problem the droplet energy equation must be coupled with the solid energy equation at the liquid-solid interface in order to obtain a solution that accounts for the temperature distribution under the droplet.

\section{CONCLUSIONS}

The evaporation of droplets in contact with hot, high thermal conductivity/diffusivity solid surfaces is studied to develop a model of the evaporative process. A model based on the assumption of uniform solid surface temperature is formulated for applications to droplets deposited on solids with large thermal conductivity and diffusivity. The droplet shape is successfully characterized using a spherical segment. The energy equation written for the droplet and at the liquid-vapor interface allows the determination of the evaporation time in reasonable agreement with experimental data. Further validation of the model is presented to describe the spatial and temporal behavior of the evaporative heat flux. 


\section{ACKNOWLEDGMENTS}

This research is supported by a grant of the Center for Fire Research of the National Bureau of Standards. The authors are deeply indebted to Professor Michiyoshi for his prompt and courteous comments on the experimental data reported in his papers. The Computer Science Center of the University of Maryland provided funding for the numerical computation.

\section{REFERENCES}

[1] Seki, M•, Kawamura, H•, and Sanokawa, K., Transient Temperature Profile of a Hot Wall Due to an Impinging Liquid Droplet, J. Heat Transfer, 100, 176 (1978).

[2] Michiyoshi, I. and Makino, K., Heat Transfer Characteristics of Evaporation of a Liquid Droplet on Heated Surfaces, Int. J. Heat Mass Transfer, 21, 605 (1978).

[3] Makino, K. and Michiyoshi, I., Effects of the Initial Size of Water Droplet on Its Evaporation on Heated Surfaces, Int. J. Heat Mass Transfer, 22, 979 (1979).

[4] Michiyoshi, I., private communication (1985).

[5] Zhang, N. and Yang, W.J., Natural Convection in Evaporating Minute Drops, J. Heat Transfer, 104, 656 (1982).

[6] Bonacina, C., De1 Giudice, S., and Comini, G., Dropwise Evaporat1on, J. Heat Transfer, 101, 441 (1979).

[7] Rizza, J.J., A Numerical Solution to Dropwise Evaporation, J. Heat Transfer, 103, 501 (1981).

[8] Chilton, T.H. and Colburn, A.P., Mass Transfer (Absorption) Coefficients - Prediction Data on Heat Transfer Fluid Motion, Ind. Eng. Chem., 26, 1183 (1934).

[9] Trehan, A.K., diMarzo, M., and Evans, D.D., Transient Cooling of a Hot Surface by Droplet Evaporation, Proc. Eastern Session Combustion Institute, Fall Technical Meeting, 61-1 (1985).

[10] Scriven, L.E. and Sternling, C.V., The Marangoni Effect, Nature, 187, 186 (1960). 


\section{NOMENCLATURE}

droplet thickness at its apex

shape function parameters

specific heat

mass diffusivity

solid-to-air heat transfer coefficient

water-to-a1r mass transfer coefficinet

thermal conductivity

molecular weight

heat $\mathrm{flux}$

radial coordinate tangent to the solid surface originating at the center of the wetted area

radius of the wetted area (constant during the evaporation time: $R=R_{0}$ )

non-dimensional thickness of the droplet $(y / R)$

time

temperature

droplet volume

vapor molar flux

vapor molar fraction

coordinate normal to the solid surface originating at the center of the wetted area

non-dimensional radius $(r / R)$

thermal diffusivity

wetting parameter (the ratio of the wetted area diameter to the diameter of a spherical droplet of equivalent volume)

shape parameter

solid-1iquid contact angle 
$\Lambda$

$\rho$

Subscripts

a

c

e

i

o

s

w latent heat of vaporization

density

air

cumulative or total

evaporative

interface

initial value (at $t=0$ )

solid or solid surface

water 

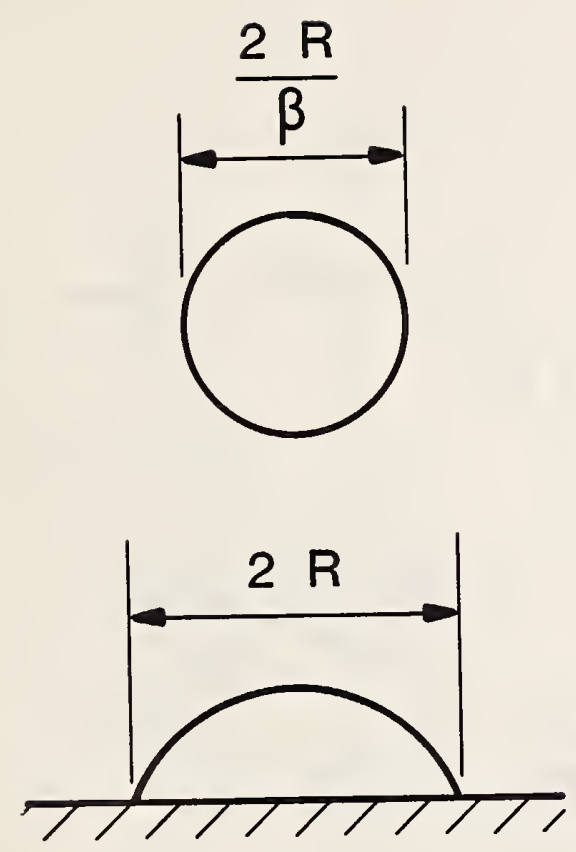

\section{ШШШШШШШШШ time $=0$}

ШШШШШШШШШШ

$$
\text { time }=10 \mathrm{~s}
$$

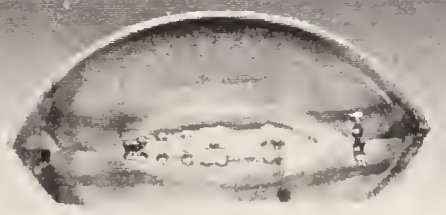

Initial Droplet Vol. $=30 \times 10^{-9} \mathrm{~m}^{3}$ Total Evap. Time (meas.) $=57 \mathrm{~s}$ ( $T$ he spacing between two grid marks on the scale is $5 \times 10^{-4} \mathrm{~m}$ )
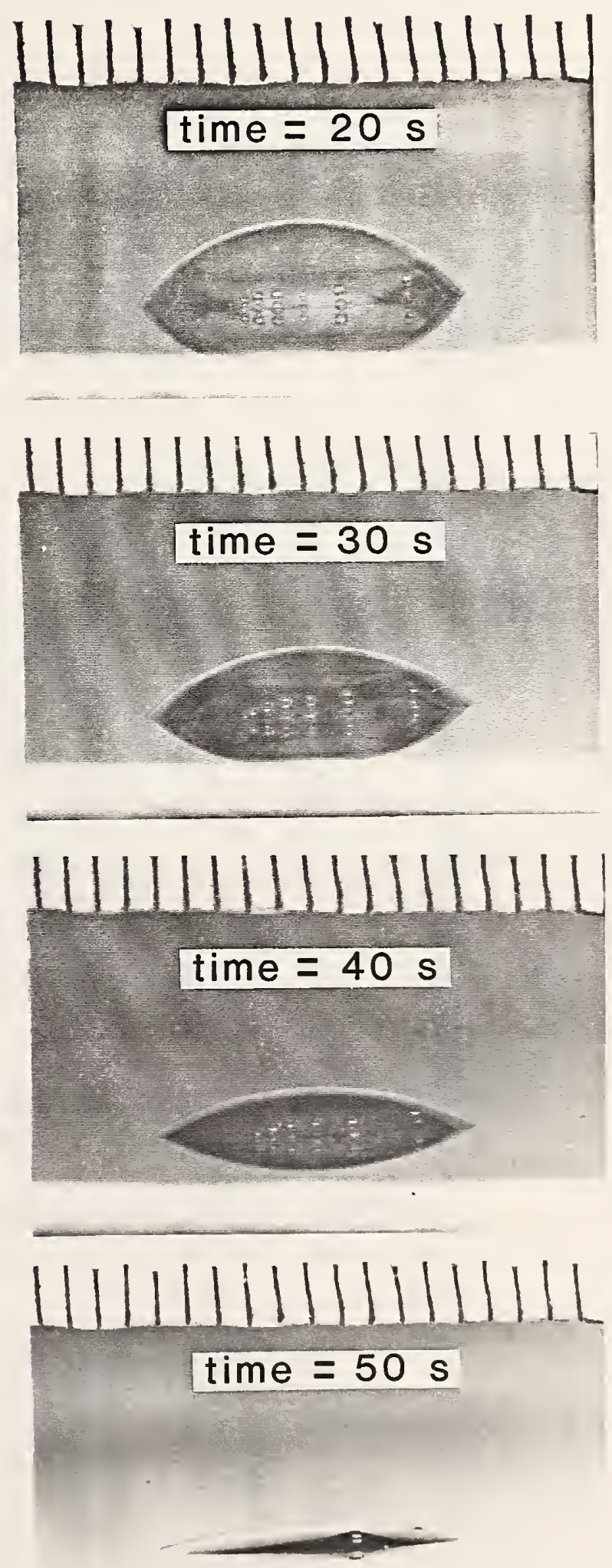

Initial Surface Temp. $=98^{\circ} \mathrm{C}$ Total Evap. Time (calc.) $=51 \mathrm{~s}$ 


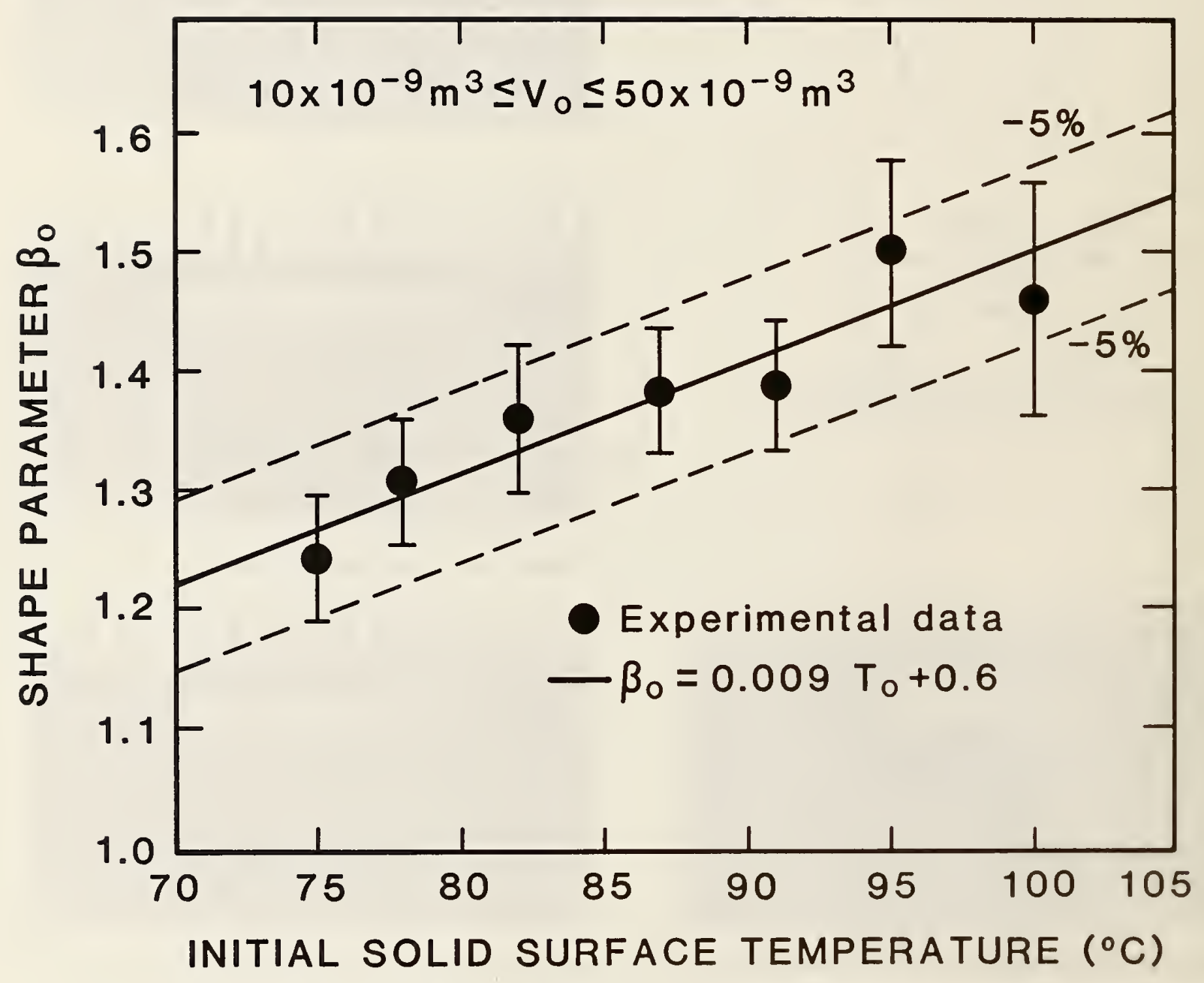

FIGURE TWO 


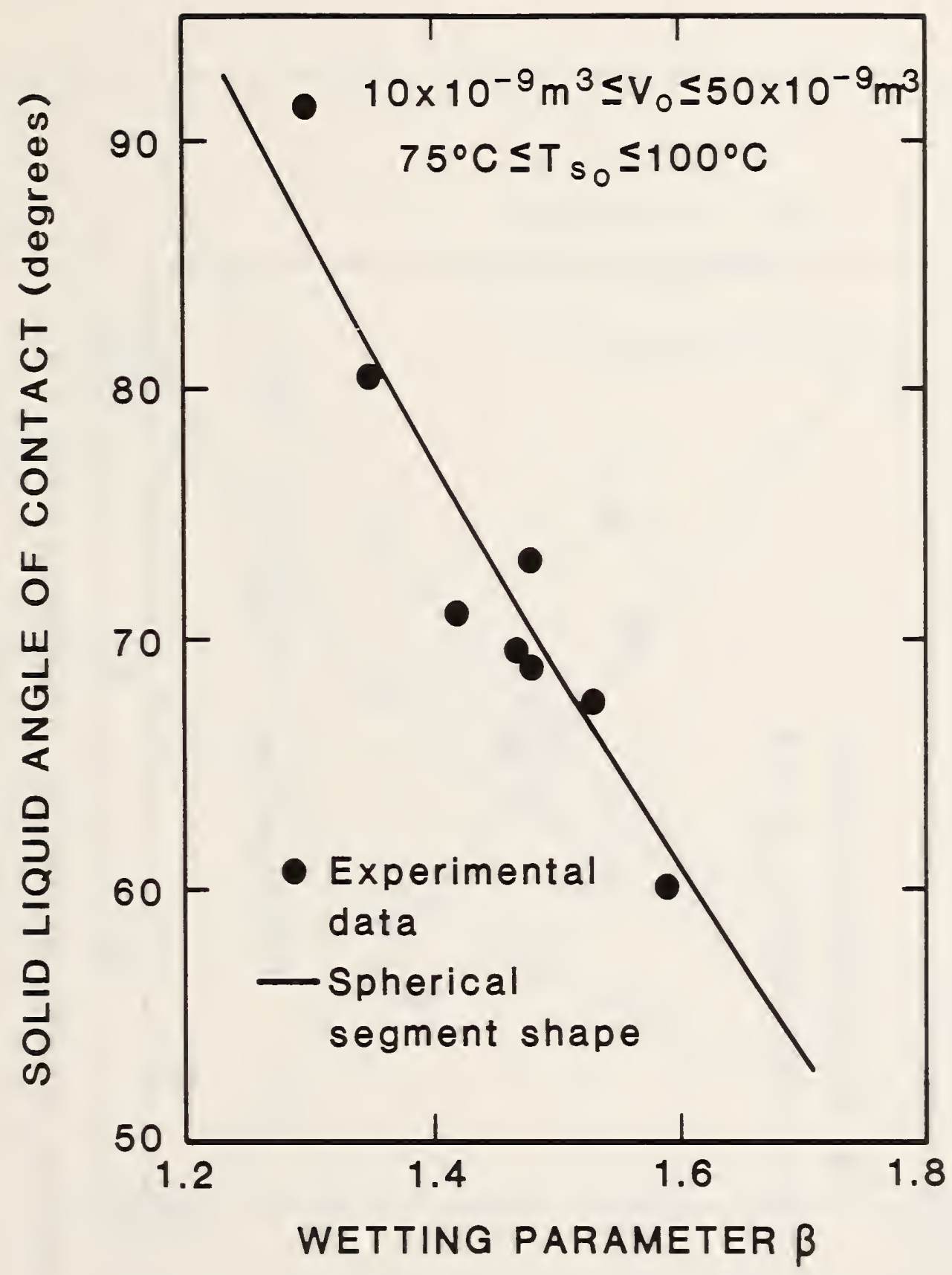




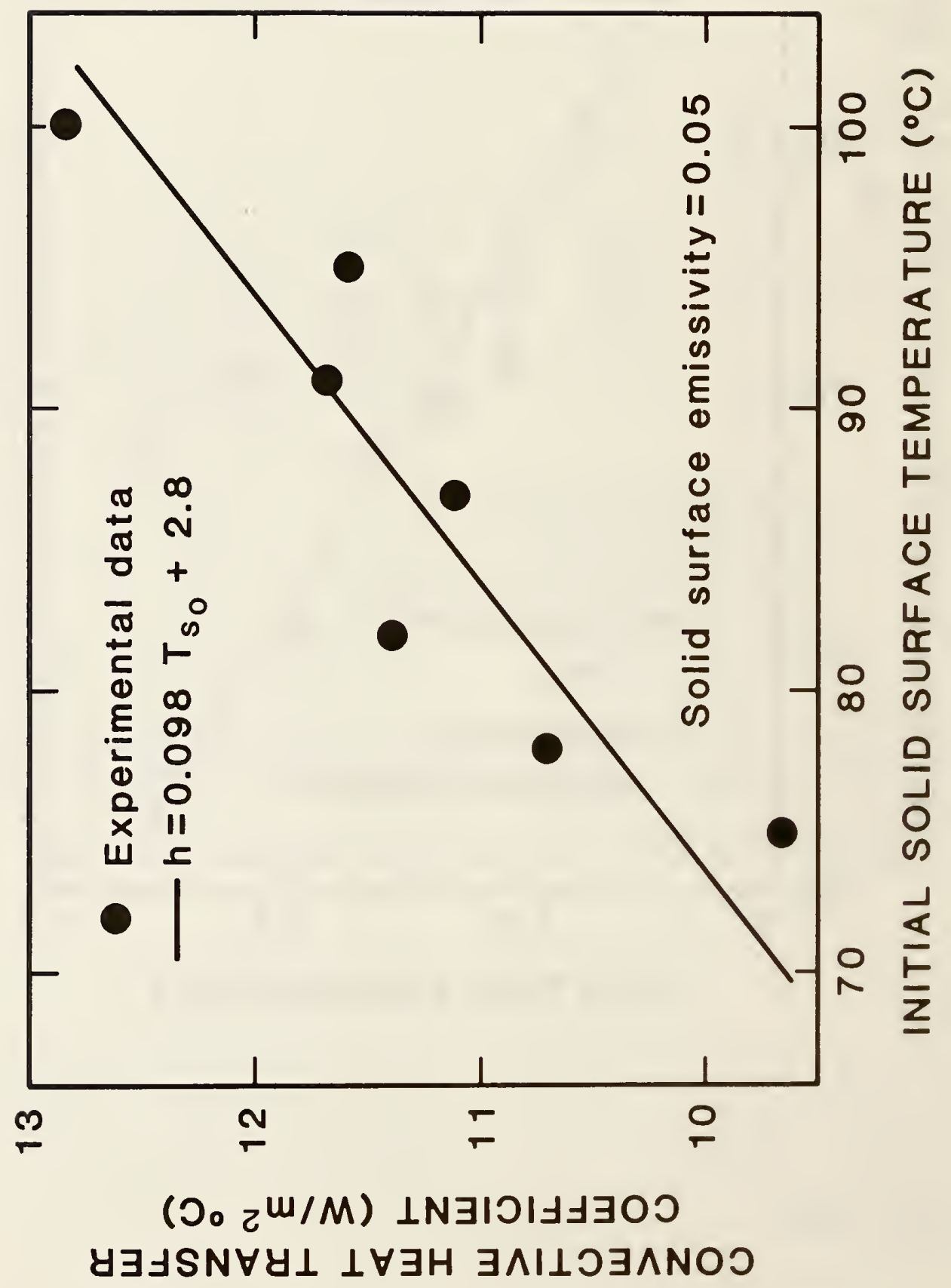




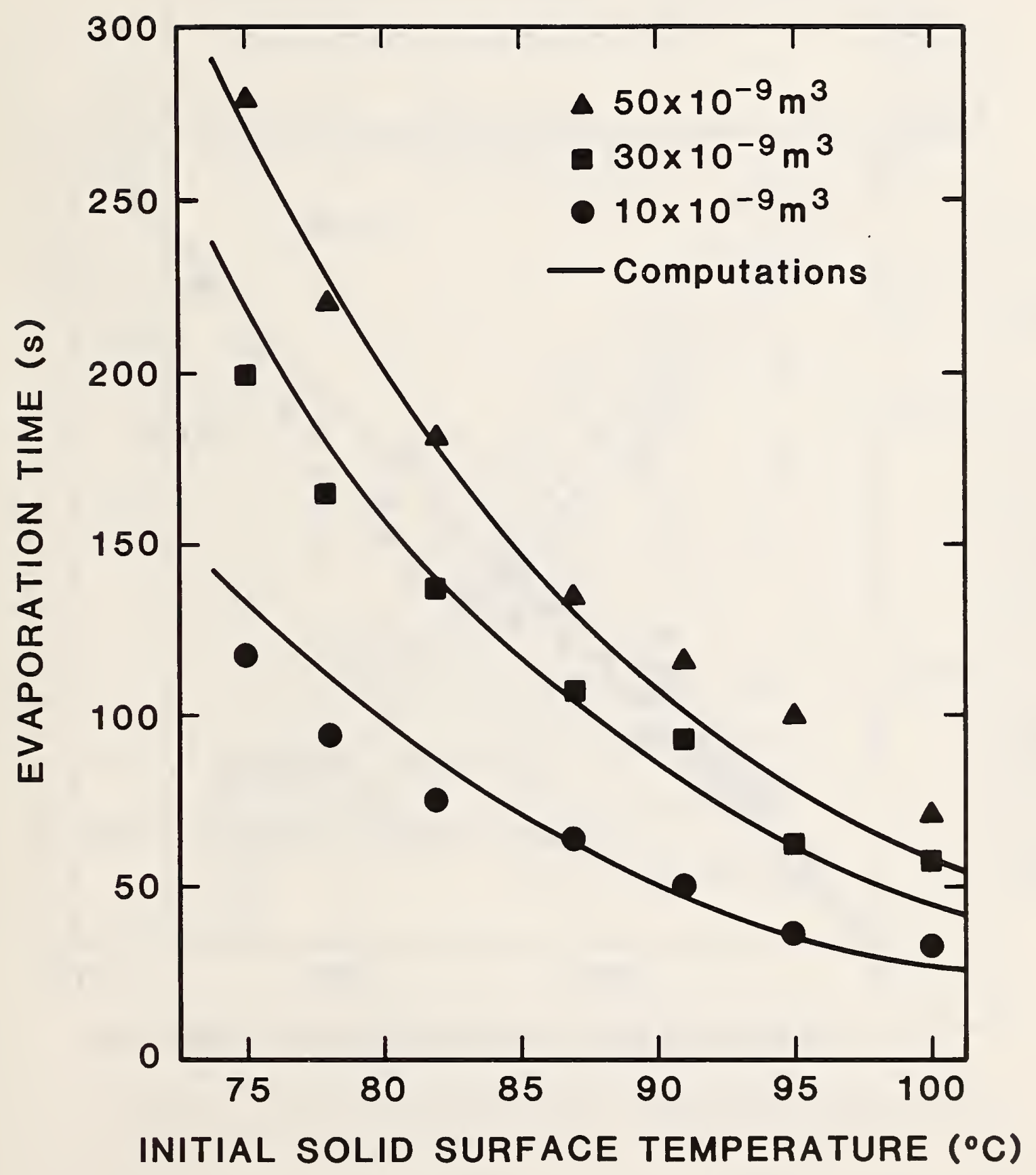

FIGURE FIVE 


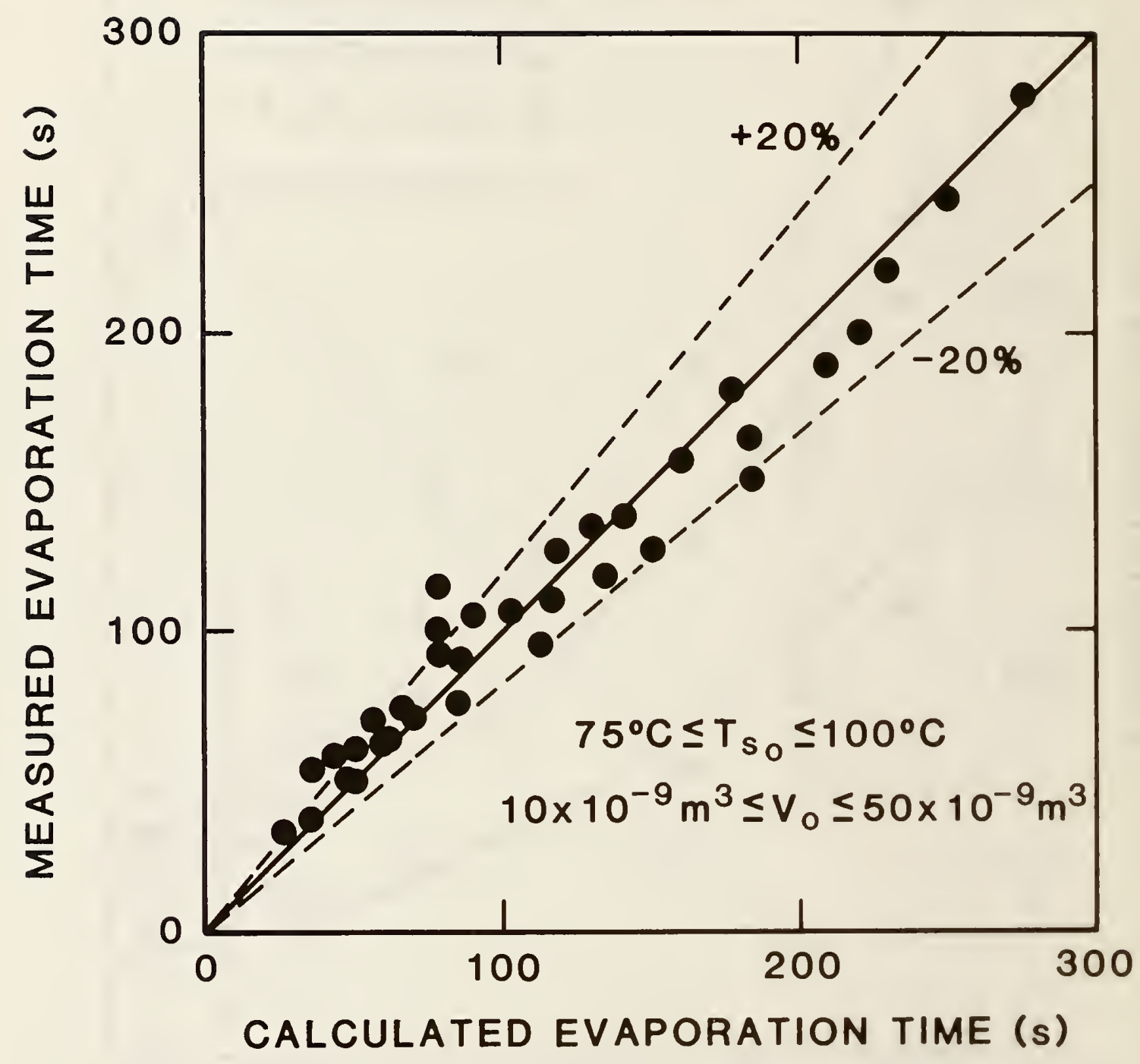

FIGURE SIX 


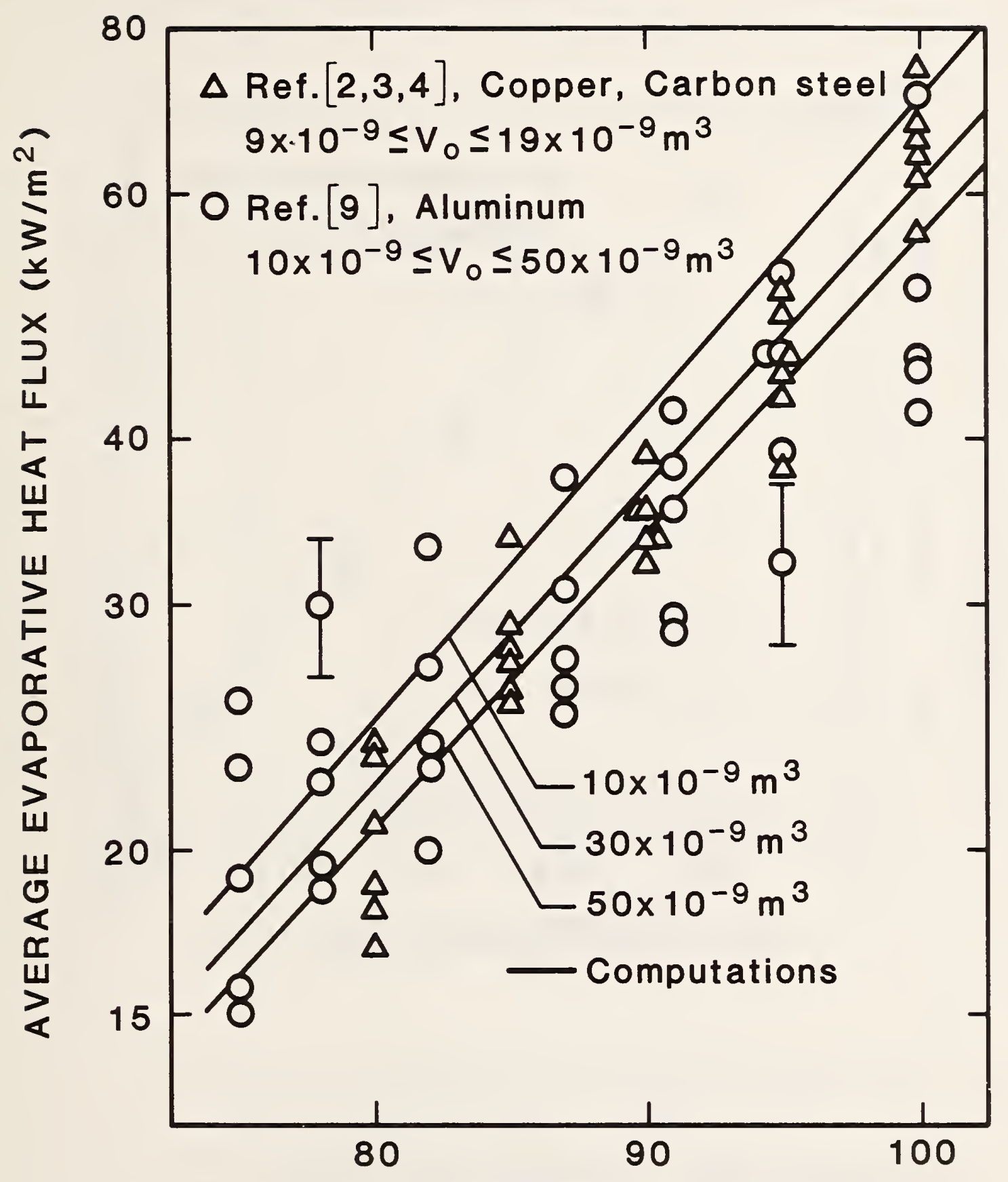

INITIAL SOLID SURFACE TEMPERATURE $\left({ }^{\circ} \mathrm{C}\right)$ 


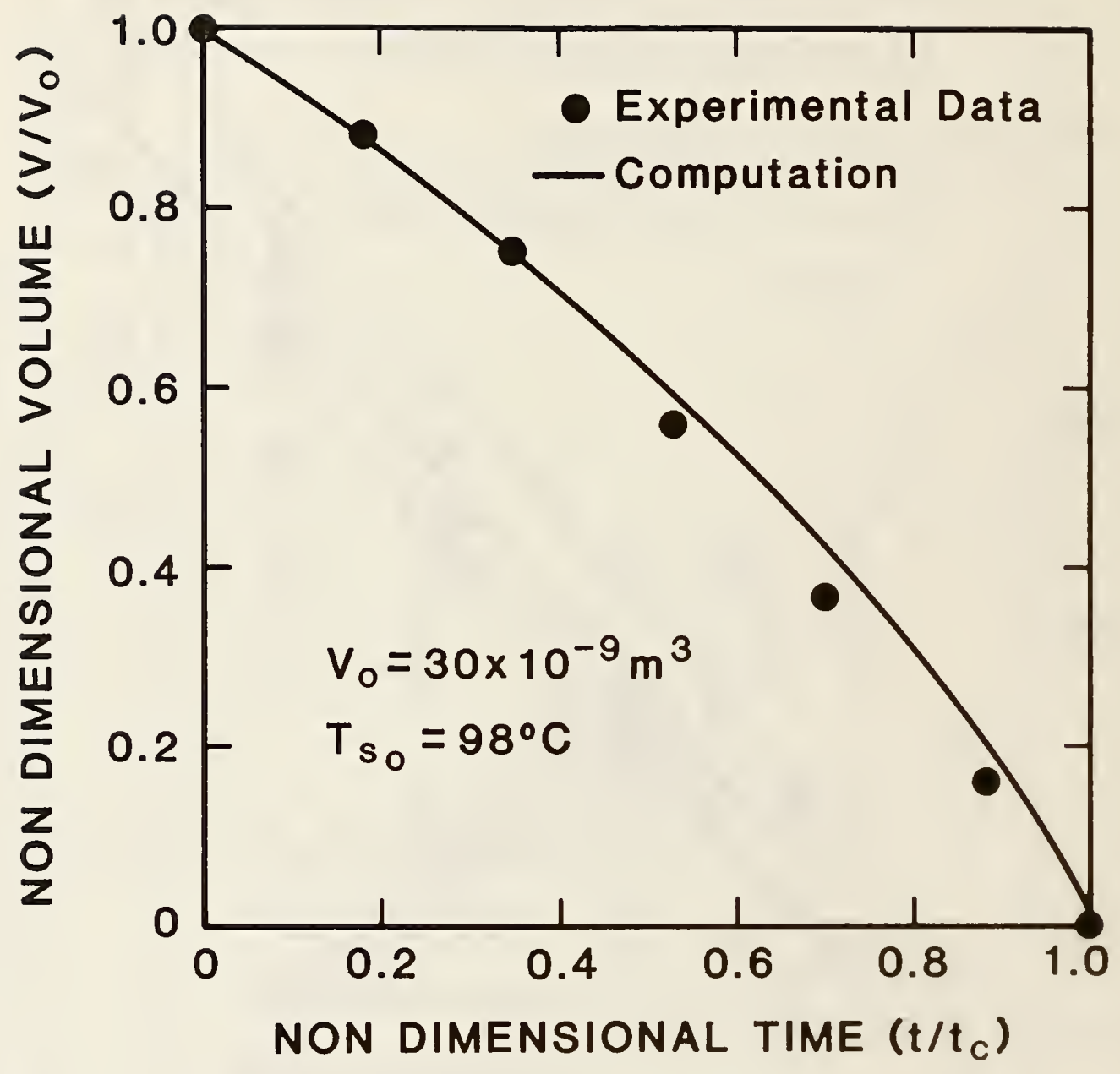

FIGURE EIGHT 


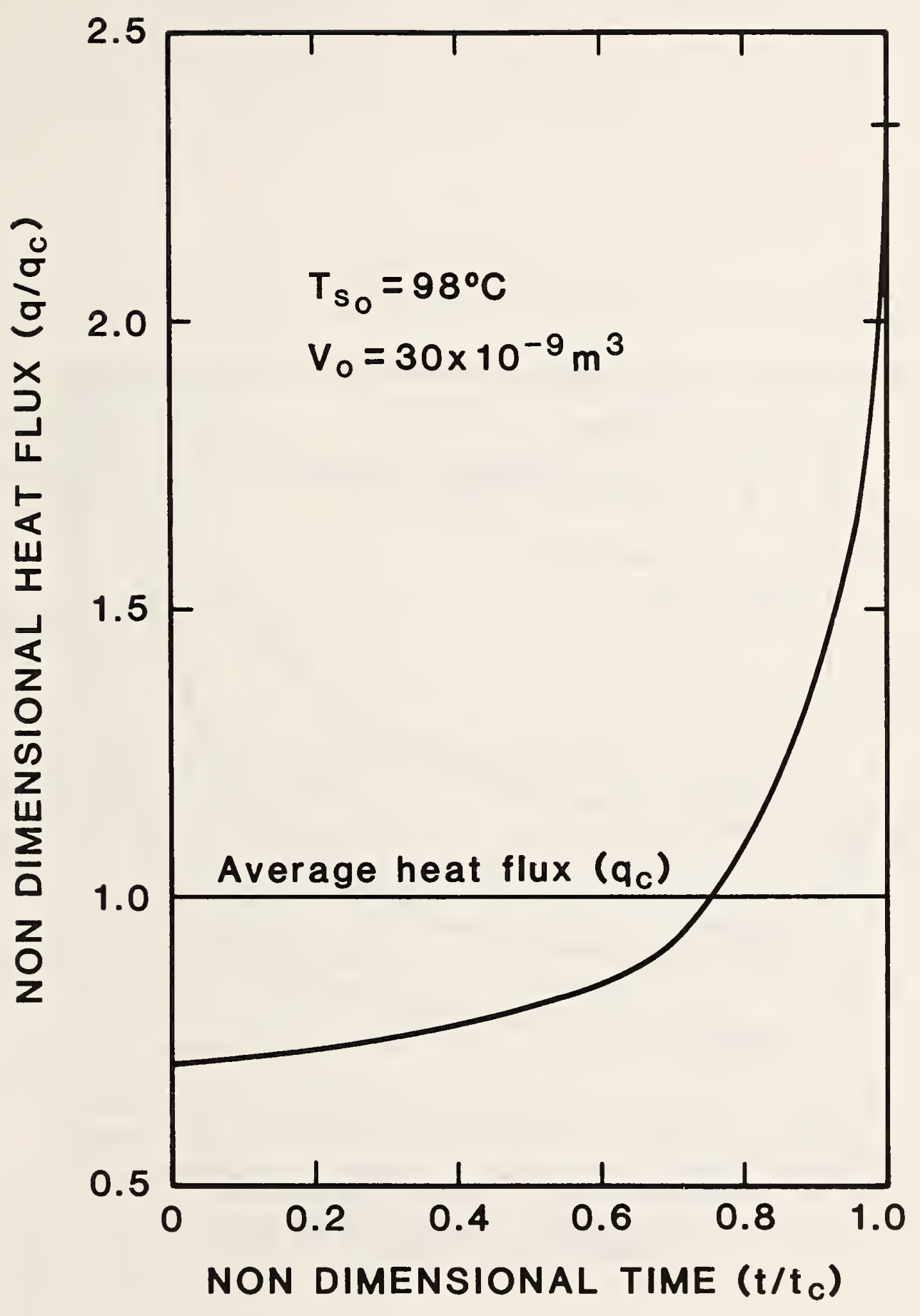

FIGURE NINE 


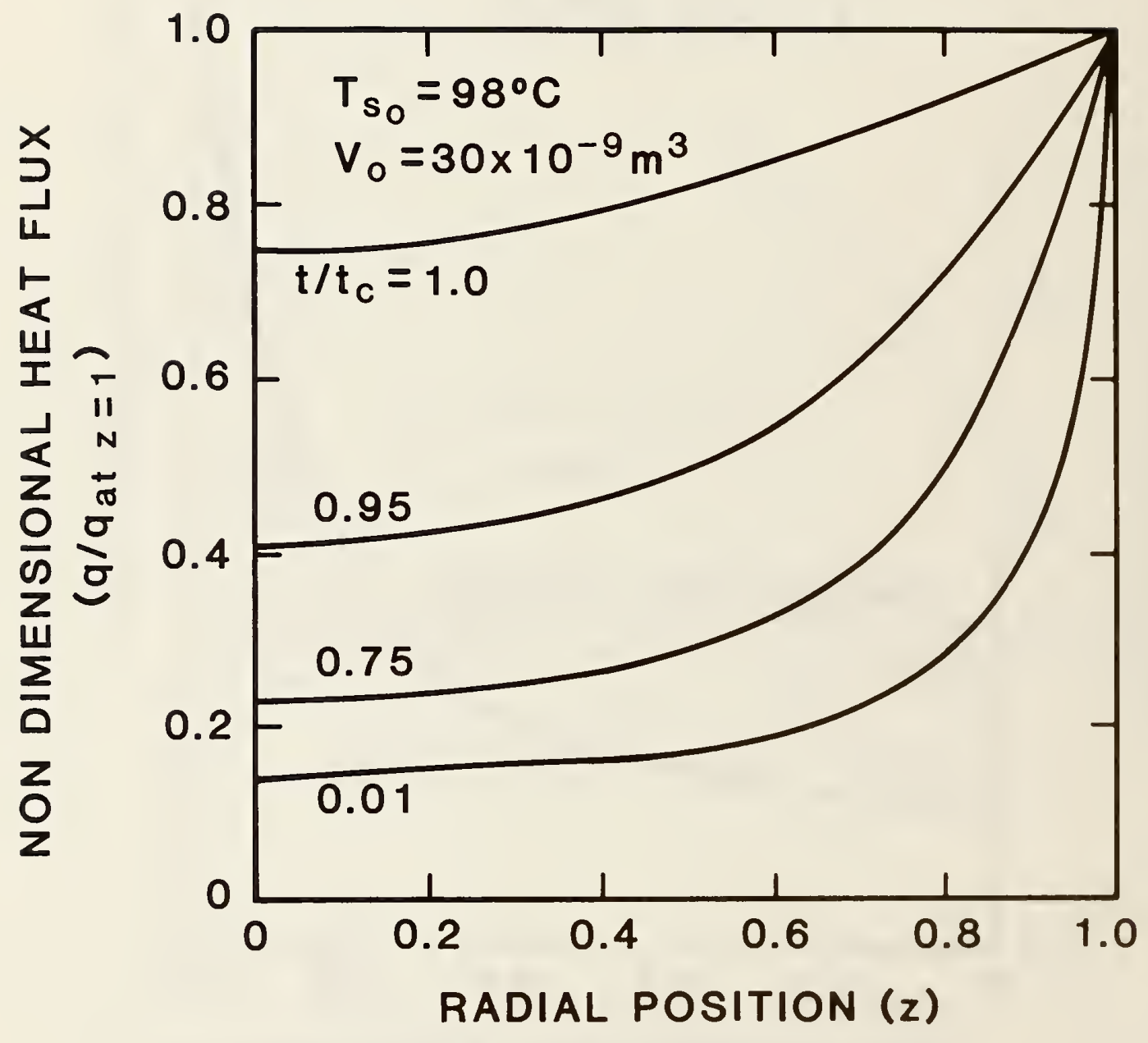

FIGURE TEN 
BIBLIOGRAPHIC DATA

SHEET (See in structions)

$$
\begin{aligned}
& \text { 1. PUBLICATION OR } \\
& \text { REPORT NO. } \\
& \text { NBSIR-86/3384 }
\end{aligned}
$$

2. Performing Organ. Report No.

3. Publication Date

August 1986

4. TITLE AND SUBTITLE

Evaporation of a Water Droplet Deposited on a Hot High Thermal Conductivity Solid Surface

5. $\operatorname{AUTHOR}(S)$

Marino di Marzo and David D. Evans

6. PERFORMING ORGANIZATION (If joint or other than NBS, see instructions)

NATIONAL BUREAU OF STANDARDS

DEPARTMENT OF COMMERCE

Gaithersburg, MD 20899

Mechanical Engr. Dept.

University of Maryland

College Park, MD 20742

7. Contract/Grant No.

9. SPONSORING ORGANIZATION NAME AND COMPLETE ADDRESS (Street, City, State, ZIP)

8. Type of Report \& Period Covered

10. SUPPLEMENTARY NOTES

Document describes a computer program; SF-185. FIPS Software Summary, is attached.

11. ABSTRACT (A 200-word or less factual summary of most significant information. If document includes a significant tibliography or literature survey. mention it here)

A model is presented that predicts major features of the evaporation of water droplets deposited on a hot non-porous solid surface. In the temperature range of interest, nucleate bolling heat transfer is fully suppressed, hence the model is only concerned with the evaporative process. In the model, the solid material is assumed to have high thermal conductivity and diffusivity, so that the surface temperature under the water droplet can be considered uniform. The temperature of this portion of a larger solid surface covered by the liquid is calculated from the classic solution for contact temperature between two semi-infinite bodies. The liquid-vapor interfacial temperature and the water-vapor molar fraction in the air at the exposed surface of the water droplet are deduced from the coupled heat and mass transfer energy balance at the interface. Spatial and temporal integration of the overall droplet energy equation is used to predict the droplet evaporation time and the instantaneous evaporation rate. Model predictions for the total evaporation time and temporal variation of the droplet volume agree well with experiments performed using a heated aluminum block. The model is used to quantify spacial and temporal heat fluxes distribution at the exposed surface of the water droplet.

12. KEY WORDS (Six to twelve entries; alphabetical order; capitalize only proper names; and seporate key words by semicolons) cooling; droplets; evaporation cooling; extinguishing; spray quenching; sprinkler system; water sprays

13. AVAILABILITY

[X] Unlimited

For Official Distribution. Do Not Release to NTIS

Order From Superintendent of Documents, U.S. Government Printing Office, Washington, D.C. 20402.

[X] Order From National Technical Information Service (NTIS), Springfield, VA. 2216I
14. NO, OF

PRINTED PAGES

33

15. Price

$\$ 9.95$ 


